\title{
Predominant porB1A and porB1B genotypes and correlation of gene mutations with drug resistance in Neisseria gonorrhoeae isolates in Eastern China
}

\author{
Aihua Sun ${ }^{1,2,3}$, Xingli Fan ${ }^{2}$, Ye Gu${ }^{4}$, Peng Du' ${ }^{1,2,3}$, Renxian Tang ${ }^{5}$, Yafei Mao ${ }^{1,3}$, Xuai Lin ${ }^{1,3}$, Jie Yan ${ }^{1,3^{*}}$
}

\begin{abstract}
Background: Variations of porB1A and porB1B genes and their serotypes exist in Neisseria gonorrhoeae isolates from different geographical areas, and some site mutations in the porB1B gene correlate with drug resistance.

Methods: The $\beta$-lactamase production of $N$. gonorrhoeae isolates was determined by paper acidometric test and nitrocefin discs. The porB1A and porB1B genes of 315 non-penicillinase-producting N. gonorrhoeae (non-PPNG) strains were amplified by PCR for sequencing to determine serotypes and site mutations. A duplex PCR was designed to simultaneously detect both porB1A and porB1B genes. Penicillin and tetracycline resistance was assessed by an in vitro drug sensitivity test.

Results: Of the N. gonorrhoeae isolates, 31.1\% tested positive for porB1A and 68.9\% for porB1B genes. All the 98 porB1 $A^{+}$isolates belonging to IA6 serotype with either no mutation at the 120 and 121 sites (88.8\%) or a D120G (11.2\%) mutation and were no resistance to both penicillin and tetracycline. Among the 217 porB1 $B^{+}$isolates, $26.7 \%, 22.6 \%$ and $11.5 \%$ belonged to IB3, IB3/6 and IB4 serotypes, respectively. Particularly, two novel chimeric serotypes, IB3/6-IB2 and IB2-IB4-IB2, were found in 77 and 8 porB1B ${ }^{+}$isolates. Two hundred and twelve (97.7\%) of the porB1 $B^{+}$isolates were presented G120 and/or A121 mutations with 163 (76.9\%) at both sites. Interestingly, within the 77 porB1B ${ }^{+}$isolates belonging to IB3/6-IB2 serotype, 15 were discovered to possess novel deletions at both A121 and N122 sites. All the replacement mutations at these sites in PorB1B were correlated with resistance and the deletion mutation showed the highest resistance.

Conclusion: N. gonorrhoeae isolates circulating in Eastern China include a sole PorB1A serotype (IA6) and five PorB1B serotypes. Multiple mutations in porB1B genes, including novel A121 and N122 deletions, are correlated with high levels of penicillin and tetracycline resistance.
\end{abstract}

\section{Background}

Gonorrhoea caused by infection with Neisseria gonorrhoeae is a global sexually transmitted disease. In Chinese populations, gonorrhoea is the most common sexually transmitted disease which causes a serious public health problem [1-5].

The outer membrane of $N$. gonorrhoeae bears many proteins such as porins that have been studied in

\footnotetext{
* Correspondence: Med_bp@zju.edu.cn

'Division of Basic Medical Microbiology, State Key Laboratory for Diagnosis and Treatment of Infectious Diseases, the First Affiliated Hospital of Zhejiang University, Zhejiang 310003, Hangzhou, China

Full list of author information is available at the end of the article
}

considerable detail [6-10]. Gonococcal porins are a group of outer membrane proteins that occur in large amounts on the surface [11-17]. PorB1A and PorB1B porins, which have $65-80 \%$ amino acid identity, share $60 \%$ of the total gonococcal porin proteins $[12,18]$. PorB1A and PorB1B are encoded by the same allele and any particular $N$. gonorrhoeae strain expresses either PorB1A or PorB1B $[12,19,20]$. PorB1A is present in $10-30 \%$ of $N$. gonorrhoeae isolates, while PorB1B occurs in $70-90 \%$ [21,22]. PorB1A and PorB1B are the serotyping basis of $N$. gonorrhoeae and mutations are more common in porB1B gene than in porB1A gene 
$[19,22,23]$. Many investigations revealed geographical diversity of the predominant porB1A and porB1B genotypes isolates in different areas [22,24-27]. Therefore, determination of porB1A and porB1B genotype distribution in $N$. gonorrhoeae isolates in different areas is very important for providing a high index of discrimination of different gonococcal strains, identifying the circulating strains and predominant serotypes, and tracking strain transmission in sexual contacts [28-32].

$N$. gonorrhoeae easily develops resistance to many antibiotics. Previous studies demonstrated that the replacement mutations at the 120 and 121 sites in PorB1B protein enable these strains to increase their resistance to penicillin and tetracycline [33,34]. However, replacement mutations at the 120 and 121 sites in PorB1A make little contribution to resistance against the two antibiotics $[9,19]$. Thus, identification of the two resistance-related site mutations in PorB1B sequences of N. gonorrhoeae isolates, and determination of the correlation between the site mutations and drug resistance are important for chemotherapy of gonorrhoea in the clinical setting. In the present study, we established a duplex polymerase chain reaction (PCR) system to rapidly confirm the porB $1 A$ and porB1B genes in $N$. gonorrhoeae isolates from Chinese patients. And the predominant serotypes based on porB1A and porB1B genotyping of the isolates circulating in Eastern China were determined by sequence analysis. Particularly, mutation at the 120 and 121 sites in PorB1B sequence from the non-penicillinase-producting $N$. gonorrhoeae (nonPPNG) isolates, as well as the correlation between the mutation patterns and the resistance to penicillin and tetracycline, were investigated.

\section{Methods}

\section{Ethics statement}

This research was conducted in accordance with the Declaration of Helsinki, and informed consent was obtained from all patients in this study for collection of clinical specimens to isolate $N$. gonorrhoeae strains, according to a protocol approved by the Ethics Committee of Zhejiang University.

\section{Bacterial strains and growth}

The clinical $N$. gonorrhoeae strains were isolated from gonorrhea patients from 2005 to 2008 by the clinical laboratories of several hospitals in Zhejiang and Jiangsu provinces, China. All the gonococcal isolates were first identified by the hospital laboratories and subsequently rechecked by our laboratory using microscopy after Gram staining plus oxidase, catalase, and carbohydrate degradation tests [35]. The gonococci were cultured on GCB blood agar plates (bioMérieux, Co., Ltd, Shanghai, China) at $37^{\circ} \mathrm{C}$ in the presence of $5 \% \mathrm{CO}_{2}$ for $24 \mathrm{~h}$.
Staphylococcus aureus ATCC25923, Staphylococcus epidermidis ATCC12228, Streptococcus pyogenes ATCC29212, Escherichia coli ATCC25922, Pseudomonas aeruginosa ATCC27543, Klebsiella pneumoniae ATCC700603, Serratia marcescens ATCC14041, Enterobacter cloacae ATCC13047 and Proteus mirabilis ATCC25933 were used to determine the specificity of duplex PCR, and were provided by the Chinese National Institute for Control of Pharmaceutical and Biological Products, and cultured in $\mathrm{MH}$ broth (bioMrieux) at $37^{\circ} \mathrm{C}$ for $24 \mathrm{~h}$.

\section{$\beta$-lactamase detection}

Paper acidometric test was applied by the clinical laboratories of hospitals to primarily detect the $\beta$-lactamase production of gonococcal isolates [5], and subsequently BBL(tm) Cefinase(tm) Paper Disc (BD, USA) based on nitrocefin coloration was used by our laboratory to further determine the production of gonococcal $\beta$-lactamase [36]. Among all the N. gonorrhoeae isolates, 315 strains were identified as non-PPNG that were used in this study.

\section{DNA preparation}

The gonococci and the other bacteria were collected by centrifugation and washed twice with phosphate buffered saline (PBS). Genomic DNA of each precipitated strain was extracted with a bacterial genomic DNA extraction kit (BioColor Inc., Shanghai, China) and then dissolved in TE buffer for detecting the DNA concentration with ultraviolet (UV) spectrophotometry [37].

\section{Amplification of entire porB1A and porB1B genes}

One pair of forward (porB1A/1B-F) and reverse (porB1A/1B-R) primers was used to amplify both the entire porB1A and porB1B genes in genomic DNA of the gonococcal isolates because they have the same nucleotide sequences at the 5 ' and 3' terminals (Table 1) [19,38,39]. A High Fidelity PCR Kit (TaKaRa Co., Ltd, Dalian, China), in which a Taq-Pfu mixture was used as the DNA polymerase, was used to amplify the two target genes. PCR was initiated by incubation at $94^{\circ} \mathrm{C}$ for 5 min, followed by 30 cycles at $94^{\circ} \mathrm{C}$ for $30 \mathrm{~s}, 54^{\circ} \mathrm{C}$ for 30 $\mathrm{s}$ and $72^{\circ} \mathrm{C}$ for $90 \mathrm{~s}$ to amplify each the two genes, and then incubation at $72^{\circ} \mathrm{C}$ for $10 \mathrm{~min}$. The products in $1.5 \%$ ethidium bromide pre-stained agarose gel after electrophoresis were observed under UV light. The target products are predicted to be $981 \mathrm{bp}$ (entire porB1A gene) and $1044 \mathrm{bp}$ (entire porB1B gene).

\section{Sequencing and genotyping}

The PCR products of the entire porB1A and porB1B genes from the $N$. gonorrhoeae isolates were purified with a PCR products purification kit (BioColor) and 


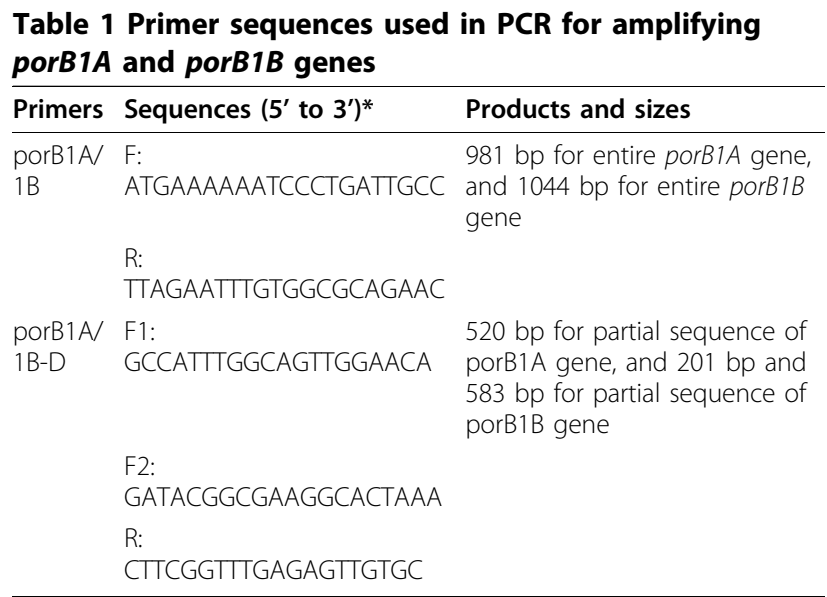

* F: forward primer, R: reverse primer

then ligated into plasmid pMD-18- $\mathrm{T}$ to form recombinant $\mathrm{pMD}-18-\mathrm{T}^{\text {porB1A }}$ and $\mathrm{pMD}-18-\mathrm{T}^{\text {porB1B }}$ with a T-A cloning kit (TaKaRa). The inserted target segments in recombinant plasmids were sequenced using the doublestranded dideoxy chain termination method by Invitrogen Co., Ltd, Shanghai, China. The obtained sequencing data were analyzed as well as compared to the sequences of PorB1A and PorB1B serotypes published in GenBank using Clustalx software.

\section{Duplex PCR}

The sequencing data of porB1A and porB1B genes from the $N$. gonorrhoeae isolates showed that these genes have over $80 \%$ identity at the 5' terminal sequences (1-240 bp segments in both genes) and approximately $90 \%$ identity at the 3' terminal sequences (714-981 bp segment in porB1A gene and 777-1044 bp segment in porB1B gene). However, a 63 bp segment in the middle region of por $B 1 B$ gene that was absent in porB1A gene enabled us to design a specific forward primer only for detecting the por $B 1 B$ gene. Thus, by using two different forward primers (20 pmol porB1A/1B-D-F1 and 20 pmol porB1A/1B-D-F2) and one common reverse primer (20 pmol porB1A/1B-DR) (Table 1), a duplex PCR system was established to simultaneously detect the porB $1 A$ and por $B 1 B$ genes in the gonococcal isolates. The total volume per duplex PCR was a $50 \mu \mathrm{l}$ mixture in which $100 \mathrm{ng}$ DNA template was used. The PCR was initiated by incubation at $94^{\circ} \mathrm{C}$ for 3 min, followed by 35 cycles at $94^{\circ} \mathrm{C}$ for $30 \mathrm{~s}, 54^{\circ} \mathrm{C}$ for $30 \mathrm{~s}$ and $72^{\circ} \mathrm{C}$ for $60 \mathrm{~s}$, and then incubation at $72^{\circ} \mathrm{C}$ for $7 \mathrm{~min}$. In agarose gel, the por $B 1 A$ gene product presented a 520 bp fragment and the por $B 1 B$ gene product showed two fragments of $201 \mathrm{bp}$ and $583 \mathrm{bp}$.

\section{Drug sensitivity test}

Susceptibility of the $N$. gonorrhoeae isolates to penicillin (bioMérieux) and tetracycline (bioMérieux) was assessed on GC agar plates (bioMérieux) by the standard proportion method [33,34]. Briefly, each freshly cultured isolate was suspended in GC broth to a density of $10^{4} / \mu \mathrm{l}$, and 5 $\mu \mathrm{l}$ of gonococcal suspension was spotted onto GC agar plates containing increasing concentrations of penicillin or tetracycline $(0.03,0.06,0.12,0.25,0.5,1,2,4,8,16$, $32,64$ and $128 \mu \mathrm{g} / \mathrm{ml})$. After inoculation, the plates were incubated at $37^{\circ} \mathrm{C}$ in $5 \% \mathrm{CO}_{2}$ for $24 \mathrm{~h}$. The minimal inhibitory concentration (MIC) was defined as the minimum concentration of antibiotic at which no more than 5 colonies were observed after incubation. A MIC value $\geq 2 \mathrm{mg} / \mathrm{L}$ was considered as resistance to the antibiotics $[40,41]$. This test was repeated as three independent experiments.

\section{Results}

Sensitivity and specificity of duplex PCR

In our duplex PCR, porB1A and porB1B gene segments were effectually amplified when using a DNA concentration of $N$. gonorrhoeae as low as $10 \mathrm{ng}$, and negative results were shown when using 10 to 500 ng DNA templates of S.aureus ATCC25923, S. epidermidis ATCC12228, S. pyogenes ATCC29212, E. coli ATCC25922, P. aeruginosa ATCC27543, K. pneumoniae ATCC700603, S. marcescens ATCC14041, E. cloacae ATCC13047 and P. mirabilis ATCC25933.

\section{Distribution of porB1A and porB1B genes in $N$. gonorrhoeae isolates}

Of the $315 N$. gonorrhoeae isolates tested, 31.1\% (98/315) and $68.9 \%(217 / 315)$ were found by separate PCR to possess por $B 1 A$ and porB1B genes, respectively. The duplex PCR established in this study accurately distinguished the por $B 1 A$ and porB1B genes (Figure 1), and presented the same positive rates for porB1A $(31.1 \%)$ and porB $1 B$ $(68.9 \%)$ genes in the same gonococcal isolates.

\section{porB1A serotype in $N$. gonorrhoeae isolates}

Compared to the por $B 1 A$ sequences belonging to different PorB1A serotypes in GenBank, all the 98 porB1 $A^{+}$ isolates had $99.47 \%$ to $100 \%$ nucleotide sequence identity and $99.04 \%$ to $100 \%$ amino acid sequence identity to the IA-6 serotype (GenBank accession No.: L19962, IA-6 serotype) (Figure 2) [19].

\section{porB1B serotypes in $N$. gonorrhoeae isolates}

Compared to the reported porB1B sequences belonging to different serotypes in GenBank [31,32], 26.7\% (58/ $217), 22.6 \%(49 / 217)$ and $11.5 \%(25 / 217)$ of the 217 porB $1 B^{+}$gonococcal isolates belonged to serotypes IB3, IB3/6, and IB4, respectively. Some $(35.5 \% ; 77 / 217)$ of the porB1B ${ }^{+}$isolates were chimeras of the IB3/6 and IB2 serotypes (IB3/6-IB2 serotype) in which about half the sequences from the 5 ' terminal were like the IB3/6 


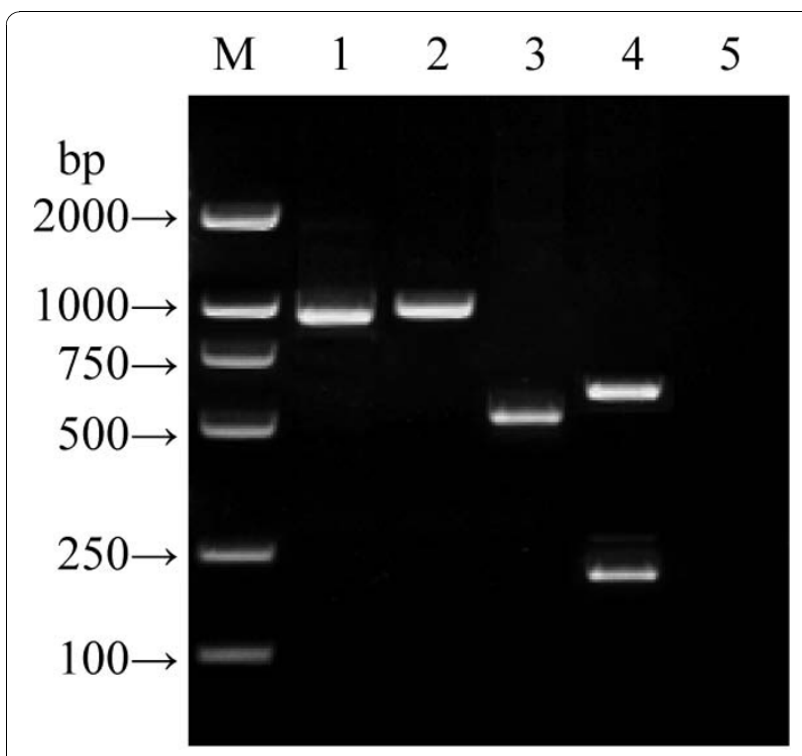

Figure 1 Amplicons of entire or partial porB1A and porB1B genes. Note: Lane M: DNA marker (BioColor); Lanes 1 and 2: amplicons of entire porB1A gene (981 bp) and porB1B gene (1044 bp), respectively; Lanes 3 and 4 : amplicons of partial porB1A gene (520 bp) and partial porB1B gene (583 bp and 201 bp) by duplex $\mathrm{PCR}$, respectively; Lane 5: blank control.

serotype and the rest were like the IB2 serotype. Also, $3.7 \%(8 / 217)$ of the porB $1 B^{+}$isolates were chimeras of the IB2 and IB4 serotypes (IB2-IB4-IB2 serotype) in which the sequence in the middle was like the IB4 serotype but those at the two terminals were like the IB2 serotype (Figure 3).

\section{Mutations at the 120 and 121 sites in PorB1A and PorB1B} Mutations at the 120 and 121 sites in PorB1A and PorB1B sequences from all $315 \mathrm{~N}$. gonorrhoeae isolates are listed in Table 2 . In the 98 porB $1 A^{+}$isolates, $88.8 \%(87 / 98)$ had D120 and G121 in the PorB1A sequences which is identical to those in the reported PorB1A sequence belonging to the IA-6 serotype (GenBank accession No.: L19962) [19], and the remaining 11 porB $1 A^{+}$isolates had a D120G mutation alone (Figure 2). In the 217 porB1 $B^{+}$gonococcal isolates, only $2.3 \%(5 / 217$, three belonging to the IB3/6 serotype and two belonging to the IB3 serotype) had no mutation at the 120 and 121 sites (G120 and A121), while 97.7\% (212/217) showed various mutations at the sites. Particularly, in the 212 porB $1 B^{+}$isolates with the site mutations, 15 isolates $(6.9 \%, 15 / 217)$ belonging to the IB3/ 6 -IB2 serotype had a deletion of the amino acid residues at both 121 and 122 sites (Figure 3).

\section{Correlation between resistance and mutations at 120 and 121 sites in PorB1A and PorB1B}

The MICs of penicillin and tetracycline for all the 98 porB $1 A^{+}$gonococcal isolates were $0.06-1 \mathrm{mg} / \mathrm{L}(<2 \mathrm{mg} /$
$\mathrm{L})$, while the MICs for both antibiotics in the 5 porB $1 B^{+}$ gonococcal isolates with no mutations at the 120 and 121 sites in PorB1B were 0.12-0.5 mg/L $(<2 \mathrm{mg} / \mathrm{L})$. However, the MICs of penicillin and tetracycline in the 197 por $B 1 B^{+}$isolates with replacement mutations at the 120 and/or 121 sites were $2-8 \mathrm{mg} / \mathrm{L}$ and $2-16 \mathrm{mg} / \mathrm{L}$, respectively, and the 15 porB $1 B^{+}$isolates with deletion mutations at both the 121 and 122 sites had the highest resistance to penicillin $(\mathrm{MICs}=4-8 \mathrm{mg} / \mathrm{L})$ and tetracycline (both MICs = 4-16 mg/L) (Table 3). According to the $\mathrm{MIC}$ value $(\geq 2 \mathrm{mg} / \mathrm{L})$ that defines resistance to penicillin and tetracycline, all the porB $1 A^{+}$isolates and the 5 por $B 1 B^{+}$isolates without site mutations were no resistance to both antibiotics, while all the remaining 212 por $B 1 B^{+}$isolates with different site mutations were penicillin and tetracycline resistant.

\section{Discussion}

The porins of $N$. gonorrhoea stimulate the host immune system to produce specific antibodies which activate the complement system and promote phagocytosis to eliminate the invading gonococci $[9,42]$. Furthermore, gonococcal PorB1A and PorB1B are closely associated with transmission of gonorrhea $[38,42]$, and mutations at the 120 and 121 sites in PorB1B are related to drug resistance $[9,19,33,34]$. Thus, determination of the predominance of PorB1A and PorB1B serotypes and drug resistance-associated mutations in the por $B 1 B$ gene in different areas is important for serological diagnosis and chemotherapy of gonorrhoea.

For rapid and convenient discrimination of por $B 1 A$ and porB1B genes in $N$. gonorrhoeae isolates, we designed a duplex PCR system by which both genes were simultaneously detectable. The results indicated that the duplex PCR accurately recognizes the por $B 1 A$ and por $B 1 B$ genes in all the 315 tested isolates with high sensitivity and specificity. By using the duplex PCR, we found $31.1 \%$ of the 315 isolates tested were positive for the por $B 1 A$ gene and the por $B 1 B$ gene was detectable in $68.9 \%$ of the isolates. This porB $1 A^{+}$and porB $1 B^{+}$ proportion in $N$. gonorrhoeae isolates is close to that of previous reports $[21,22]$.

The gonococcal por $B 1 B$ gene differs from the por $B 1 A$ gene in having many more mutations in its sequence $[19,38,39]$. Among the 217 porB $1 B^{+}$isolates in this study, 77 (35.5\%), 58 (26.7\%), and 49 (22.6\%) isolates belonged to the IB3/6-IB2, IB3 and IB3/6 serotypes, and only $25(11.5 \%)$ and $8(3.7 \%)$ referred to the IB4 and IB2-IB4-IB2 serotypes, respectively. These data indicate that the predominant serotypes of porB $1 B^{+} N$. gonorrhoeae in Eastern China are IB3/6-IB2, IB3 and IB3/6 $(84.8 \%, 184 / 217)$, which quite differs from the IB2, IB4 and IB3 reported as the predominant serotypes in nations in Europe and North America [19,22-24]. Bash 


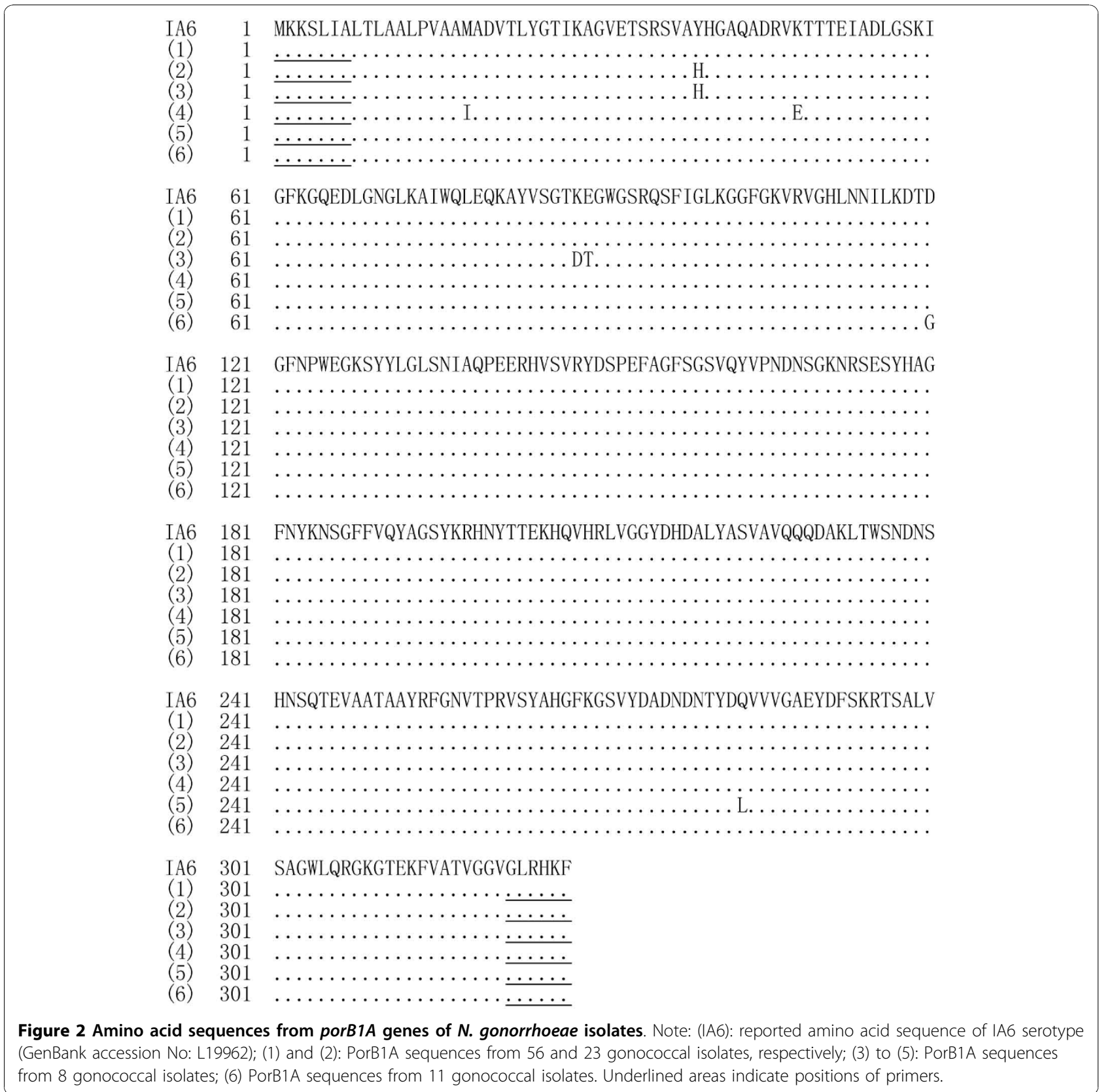

and colleagues (2005) showed that the porB1B gene has a high recombinant mutation frequency compared to the porB1A gene [43]. In our study, two novel recombinant mutations formed IB3/6-IB2 and IB2-IB4-IB2 chimeric serotypes, which also indicates a high frequency of recombination among different gonococcal por $B 1 B$ genes. There have been reports of $N$. gonorrhoeae strains that react to both PorB1A and PorB1B antibodies, raising the possibility of mosaicism between porB1 $A$ and porB1B alleles $[44,45]$. However, no such mosaicism was found in all the $N$. gonorrhoeae isolates tested in this study.
Olesky et al. (2002) used the site mutation technique to generate mutants at the 120 and 121 sites in PorB1B, and found stronger resistance to penicillin and tetracycline in the G120K, G120D/A121D, G120K/A121R and G120P/A121P mutants [46]. Among the 217 porB1B ${ }^{+}$ isolates in this study, only five had no mutations at the 120 and 121 sites, while the other 212 had various mutations at these sites, in which $76.9 \%(163 / 212)$ had double-site mutations (G120K/A120D, G120K/A121G and G120N/A121D in 135, 19 and 9 isolates). All the 212 por $B 1 B^{+}$isolates had a mutation at the G120 site replaced with lysine (K) $(76.9 \%, 163 / 212)$, aspartate (D) 


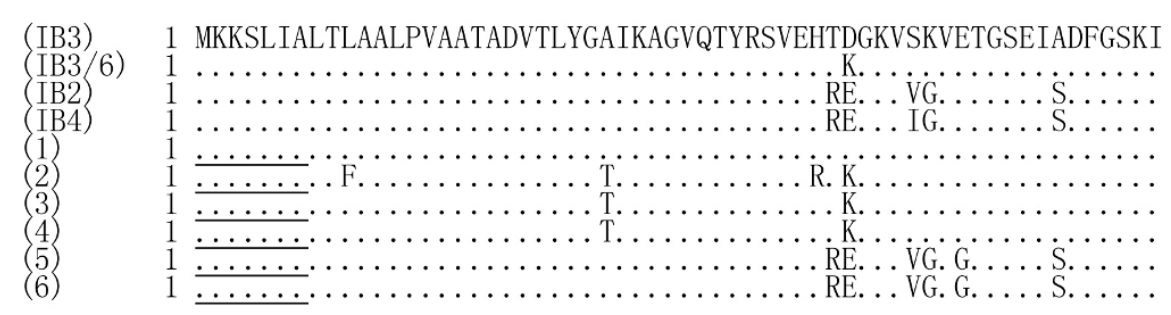

(IB3) 61 GFKGQEDLGNGLKAVWQLEQGASVAGTNTGWGNKQSFVGLKGGFGTIRAGSLNSPI KNTK

$\left.\begin{array}{l}\text { IB3) } \\ \text { IB3/6) } \\ \text { IB2 } \\ \text { IB4) } \\ 1 \\ 2 \\ 3 \\ 4 \\ 5 \\ 6\end{array}\right)$

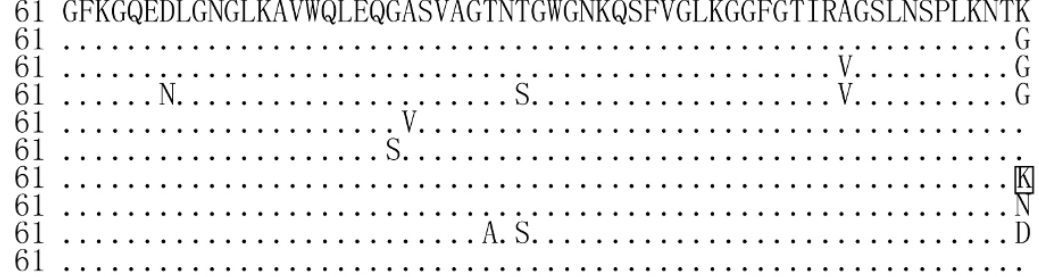

(IB3) 121 DNVNAWESGKFTGNVLEISGMAKREHRYLSVRYDSPEFAGFSGSVQYAPKDNSGSNGESY

$121 \mathrm{~A}$.

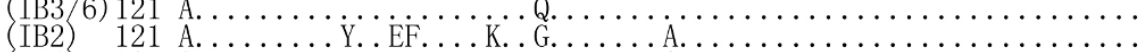

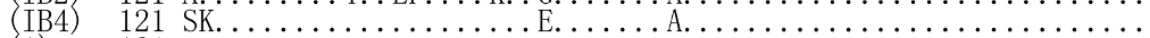

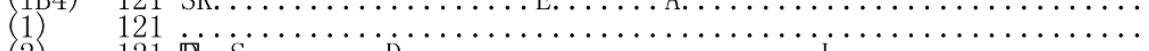

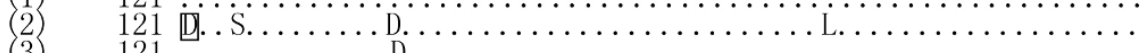

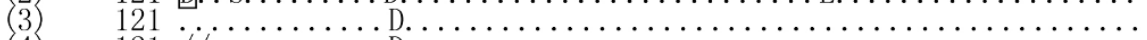

(4) $\quad \begin{aligned} & 121 \\ & 121\end{aligned}$

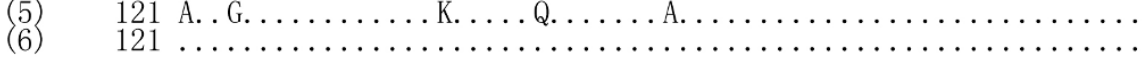

(IB3) 181 HVGLNYQNSGFFAQYAGLFQRYGEGTKKIEYDGQAYSMPSLFVEKLQVHRLVGGYDNNAL

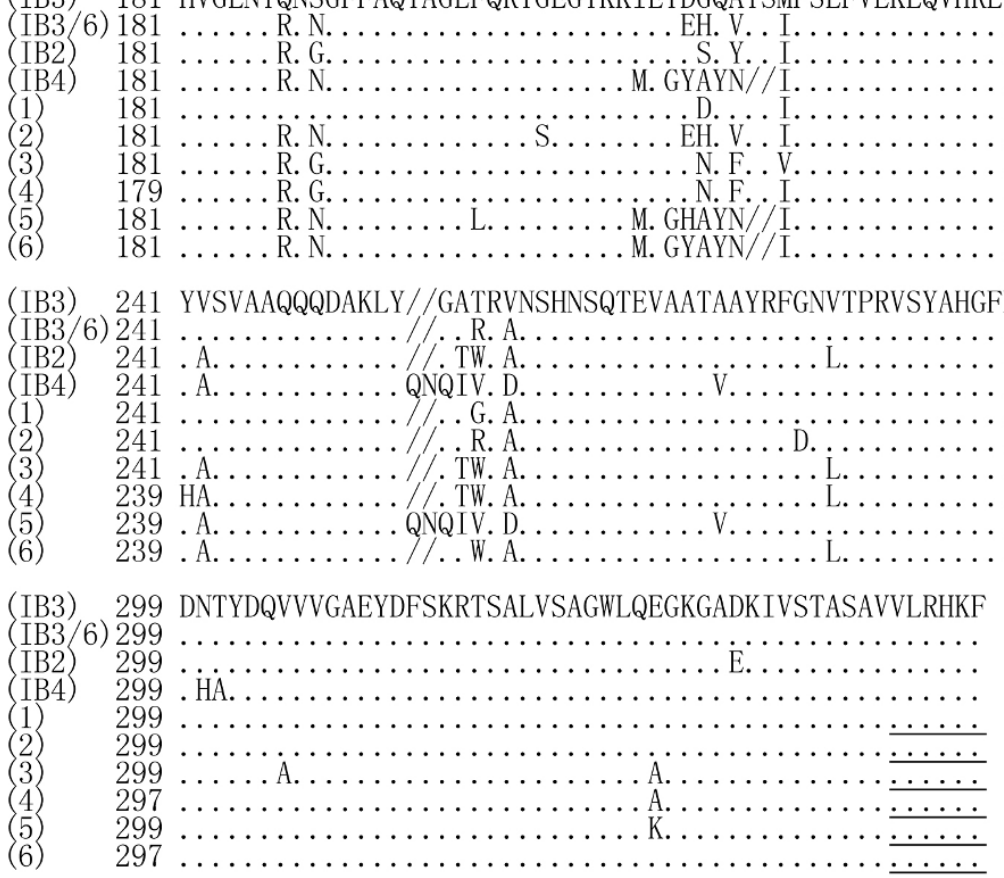

Figure 3 Amino acid sequences from porB1B genes of $\boldsymbol{N}$. gonorrhoeae strains. Note: (IB3), (IB3/6), (IB2) and (IB4): reported PorB1B sequences belonging to serotypes IB3 (GenBank accession No: U75639), IB3/6 (GenBank accession No: U75641), IB2 (GenBank No: U75640) and IB4 (GenBank No: AF090797), respectively; (1): PorB1B sequence from 58 gonococcal isolates referring to IB3 serotype; (2): PorB1B sequence from 49 gonococcal isolates referring to IB3/6 serotype (D means the 27 isolates with $A 121 D$ mutation, the 19 isolates with $A 121 G$ mutation and the remaining 3 isolates with no mutation at the A121 site); (3): PorB1B sequence from 62 gonococcal isolates referring to IB3/6-IB2 chimeric serotype without $A 121$ and $\mathrm{N} 122$ deletion (K means the 53 strains with G120K mutation and the remaining 9 strains with G120N mutation); (4): PorB1B sequence from 15 gonococcal isolates referring to IB3/6-IB2 chimeric serotype with A121 and N122 deletions; (5): PorB1B sequence from 25 gonococcal isolates referring to IB4 serotype; (6): PorB1B sequence from 8 gonococcal isolates referring to IB2-IB4-IB2 chimeric serotype. Underlined areas indicate the positions of primers. The signal "/" means lack of the amino acid residue. 
Table 2 G120 and A121 mutations in PorB1A and PorB1B of N. gonorrhoeae isolates*

\begin{tabular}{|c|c|c|c|c|c|c|c|c|c|}
\hline \multirow[t]{2}{*}{ Serotypes } & \multirow[t]{2}{*}{ Cases (n) } & \multicolumn{8}{|c|}{ Site mutation patterns (n) } \\
\hline & & G120K/A121D & G120K/A121G & G120N/A121D & G120D/A121G & G120D & G120K & G120N & A121G \\
\hline IB3 & 56 & 56 & 0 & 0 & 0 & 0 & 0 & 0 & 0 \\
\hline IB3/6 & 46 & 27 & 19 & 0 & 0 & 0 & 0 & 0 & 0 \\
\hline IB4 & 25 & 0 & 0 & 0 & 0 & 25 & 0 & 0 & 0 \\
\hline IB3/6-|B2 & 62 & 44 & 0 & 9 & 0 & 0 & 9 & 0 & 0 \\
\hline $\mathrm{IB} 3 / 6-\mathrm{IB} 2^{\#}$ & 15 & 0 & 0 & 0 & 0 & 0 & 0 & 15 & 0 \\
\hline IB2-IB4-IB2 & 8 & 8 & 0 & 0 & 0 & 0 & 0 & 0 & 0 \\
\hline IA6 & 98 & 0 & 0 & 0 & 87 & 0 & 0 & 0 & 11 \\
\hline Total & 310 & 135 & 19 & 9 & 87 & 25 & 9 & 15 & 11 \\
\hline
\end{tabular}

*: 5 isolates ( 3 for IB3/6 and 2 for IB3 serotypes) without G120 and A121 mutations not included. G, K, A, D and N indicate glycine, lysine, aspartic acid and asparagine, respectively. ": isolates with deletions of both $\mathrm{A} 121$ and $\mathrm{N} 122$.

$(11.8 \%, 25 / 212)$ or asparagine $(\mathrm{N})(11.3 \%, 24 / 212)$. On the other hand, $76.9 \%$ of the 212 porB $1 B^{+}$strains had a mutation at the A121 site replaced with aspartate (D) $(88.3 \%, 144 / 163)$ or glycine (G) $(11.7 \%, 19 / 163)$. However, the G120R, G120P, A121H and A121P mutations described by Olesky et al were not found, suggesting differences in the amino acids replacement by natural and artificial mutations. Particularly, in this study we found that 15 gonococcal isolates had A121 and N122 deletion mutations in PorB1B that had not previously been reported.

Many previous data revealed that plasmid-mediated resistance of $N$. gonorrhoeae confer the very high MICs of penicillinand tetracycline [47-49], while chromosomally mediated resistance such as the site mutations at G120 or A121 in gonococcal PorB1B contributes to the moderate higher MICs of the two antibiotics [33,34].

Table 3 MICs of penicillin and tetracycline for $\boldsymbol{N}$. gonorrhoeae isolates

\begin{tabular}{|c|c|c|c|c|}
\hline \multirow[t]{2}{*}{ Site mutations* } & \multirow[t]{2}{*}{ Serotypes } & \multirow{2}{*}{$\begin{array}{l}\text { Cases } \\
\text { (n) }\end{array}$} & \multicolumn{2}{|c|}{ MICs (mg/L) } \\
\hline & & & Penicillin & Tetracycline \\
\hline \multirow[t]{4}{*}{ G120K/A121D } & IB3 & 56 & $2-4$ & $2-8$ \\
\hline & IB3/6 & 27 & $2-4$ & $2-8$ \\
\hline & |B3/6-|B2 & 44 & $2-4$ & $2-8$ \\
\hline & IB2-|B4-|B2 & 8 & $2-4$ & $2-4$ \\
\hline G120K/A121G & $\mathrm{IB} 3 / 6$ & 19 & $2-4$ & $2-8$ \\
\hline G120N/A121D & IB3/6-|B2 & 9 & 2 & $2-4$ \\
\hline G120D & IB4 & 25 & $2-4$ & $2-8$ \\
\hline G120K & IB3/6-|B2 & 9 & $2-4$ & $2-8$ \\
\hline $\begin{array}{c}\text { G120N/A121 and N122 } \\
\text { deletion }\end{array}$ & IB3/6-|B2 & 15 & $4-8$ & $4-16$ \\
\hline \multirow[t]{2}{*}{ G120G/A121A } & IB3/6 & 3 & 0.12 & 0.25 \\
\hline & IB3 & 2 & 0.25 & 0.25 \\
\hline $\mathrm{D} 120 \mathrm{D} / \mathrm{G} 121 \mathrm{G}$ & IA6 & 87 & $0.06-0.5$ & $0.06-0.5$ \\
\hline D120G/G121G & IA6 & 11 & $0.12-0.25$ & $0.12-1$ \\
\hline
\end{tabular}

*: $G, K, A, D$ and $N$ indicate glycine, lysine, aspartic acid and asparagine, respectively.
According to our drug sensitivity tests for the nonPPNG isolates, the G120K/A121D, G120K/A121G, G120N/A121D, G120D and G120K natural porB1B mutants also had stronger resistance to penicillin and tetracycline than porB $1 B^{+}$isolates with no G120 and A121 mutations (Table 3 ). Interestingly, the 15 porB $1 B^{+}$ isolates with $\mathrm{A} 121$ and $\mathrm{N} 122$ deletions had the highest MICs, which hints at a greater influence of the A121 deletion on resistance than any of the replacement mutations. This resistance relating to chromosomallymediated site mutations in PorB1B has been shown in many previous reports $[33,46,50-52]$. However, in these reports the PorB1B mutation-associated resistance only noted MICs of penicillin and tetracycline in the range of $2-8 \mu \mathrm{g} / \mathrm{ml}$. Previous data revealed that site mutations in the pen $A, m t r R$, pon $A$, and rpsJ genes also participate in chromosomally-mediated gonococcal resistance to penicillin and tetracycline [47,53-55]. Thus, synergistic action of site mutations in multiple chromosomal genes associated with resistance in $N$. gonorrhoeae isolates is an important subject for investigation. Such action may be responsible for the high resistance to both antibiotics found in this study.

We found that all the tested porB1 $A^{+}$gonococcal isolates were no resistance to both penicillin and tetracycline, whereas $97.7 \%(212 / 217)$ of the porB1B $B^{+}$isolates had site mutation-based resistance in the PorB1B sequences. The high proportion $(100 \%)$ of resistanceassociated mutations at the 120 and 121 sites in PorB1B of $N$. gonorrhoeae isolates from other Chinese areas has also been reported $[51,52,56]$. Thus, the duplex PCR established in this study for rapid identification of por $B 1 A^{+}$and $\operatorname{por} B 1 B^{+}$gonococci provides a useful tool for selecting antibiotics to treat gonorrhea in China.

\section{Conclusions}

The duplex PCR system we designed simultaneously recognizes porB1A and porB1B genes in $N$. gonorrhoeae isolates with high sensitivity and specificity. $\operatorname{por} 1 B^{+} N$. 
gonorrhoeae is the predominant genotype in Eastern China. All the porB $1 A^{+}$isolates had the conserved por $B 1 A$ gene sequence belonging to the IA6 serotype alone. However, the $\operatorname{por} B 1 B^{+}$isolates had high site mutations in the porB1B sequence that resulted in five PorB1B serotypes. All the porB $1 A^{+}$isolates were no resistance to both penicillin and tetracycline. However, multiple penicillin and tetracycline resistance-related mutations such as G120K/A121D, G120K/A121G and G120N/A121D occurred in PorB1B isolates. A novel mutation due to deletion of both A121 and N122 in PorB1B is correlated with high resistance to penicillin and tetracycline.

\section{List of Abbreviations}

STD: sexual transmitted disease; G: glycine; D: aspartic acid; K: lysine; R: arginine; P: proline; A: alanine; $\mathrm{H}$ : histidine; $\mathrm{N}$ : asparagine; PCR: polymerase chain reaction; DNA: deoxyribonucleic acid; PBS: phosphate buffered saline: TE: Tris-EDTA; Tris: trihydroxymethyl aminomethane; EDTA: ethylenediamine tetraacetic acid; UV: ultraviolet rays; MIC: minimal inhibitory concentration

\section{Acknowledgements}

This work was supported by grants from the Science and Technical Research Project of the Health Bureau of Zhejiang Province, China (2004A018), and the State Key Laboratory for Diagnosis and Treatment of Infectious Diseases, the First Affiliated Hospital, Zhejiang University, China (2008ZZ06). We thank the hospitals in Zhejiang Province and Jiangsu Province, China, for isolating and providing the strains of $\mathrm{N}$. gonorrhoeae from patients. We also thank Dr. IC Bruce, Zhejiang University School of Medicine, for reading the manuscript.

\section{Author details}

'Division of Basic Medical Microbiology, State Key Laboratory for Diagnosis and Treatment of Infectious Diseases, the First Affiliated Hospital of Zhejiang University, Zhejiang 310003, Hangzhou, China. ${ }^{2}$ Faculty of Basic Medicine, Zhejiang Medical College, 310053 Zhejiang Hangzhou, China. ${ }^{3}$ Department of Medical Microbiology and Parasitology, College of Medicine, Zhejiang University, Zhejiang 310058, Hangzhou, China. ${ }^{4}$ College of Foreign Languages, Zhejiang Chinese Medicine University, Zhejiang 310053, Hangzhou, China. ${ }^{5}$ Department of Medical Microbiology and Parasitology, Xuzhou Medical College, Jiangsu 221009, Xuzhou, China.

\section{Authors' contributions}

AS participated in the experimental design, obtained funding for the study, performed PCR and drafted the manuscript. XF supervised the collection of gonococcal isolates, and helped to draft the manuscript. PD analyzed the sequencing data. YG helped to draft the manuscript. RT helped to collect the gonococcal isolates. YM helped to perform PCR. XL carried out the drug sensitivity tests. JY participated in the experimental design and obtained funding for the study. All authors have read and approved the final manuscript.

\section{Competing interests}

The authors declare that they have no competing interests.

Received: 4 February 2010 Accepted: 10 November 2010 Published: 10 November 2010

\section{References}

1. WHO: Global prevalence and incidence of selected curable sexually transmitted infections: overview and estimates. Geneva, WHO;2001:14-19.

2. Tazil L, Losada MP, Gu WM, Yang Y, Xue L, Crandall KA, Viscidi RP: Population dynamics of Neisseria gonorrhoeae in Shanghai, China: a comparative study. BMC Infectious Diseases 2010, 10:13.

3. Workowski KA, Berman SM: Sexually transmitted diseases treatment guidelines. MMWR Recomm Rep 2006, 55:1-94.
4. Low N, Broutet N, Sarkodie YA, Barton P, Hossain M, Hawkes S: Global control of sexually transmitted infections. Lancet 2006, 368:2001-2016.

5. Su X, Jing F, Qimuge, Dia X, Sun H, Ye S: Surveillance of antimicrobial susceptibilities in Neisseria gonorrhoeae in Nanjing, china, 1999-2006. Sex Transm Dis 2007, 34:995-999.

6. Swanson J: Surface-exposed protein antigens of the gonococcal outer membrane. Infect Immun 1981, 34:804-816.

7. Gotschlich EC, Seiff ME, Blake MS, Koomey M: Porin protein of Neisseria gonorrhoeae: cloning and gene structure. Proc Natl Acad Sci USA 1987, 84:8135-8139.

8. Ley VDP, Heckels JE, Virji M, Hoogerhout P, Poolman JT: Topology of outer membrane porins in pathogenic Neisseria spp. Infect Immun 1991, 59:2963-2971.

9. Pérez-Losada M, Viscidi RP, Demma JC, Zenilman J, Crandall KA: Population genetics of Neisseria gonorrhoeae in a high-prevalence community using a hypervariable outer membrane porB and 13 slowly evolving housekeeping genes. Mol Biol Evol 2005, 22:1887-1902.

10. Zhu WY, Thomas CE, Chen CJ, Van Dam CN, Johnston RE, Davis NL, Sparling PF: Comparison of immune responses to gonococcal PorB delivered as outer membrane vesicles, recombinant protein, or Venezuelan equine encephalitis virus replicon particles. Infect Immun 2005, 73:7558-7568.

11. Virji M, Zak K, Heckels JE: Monoclonal antibodies to gonococcal outer membrane protein IB: use in investigation of the potential protective effect of antibodies directed against conserved and type-specific epitopes. J Gen Microbiol 1986, 132:1621-1629.

12. Carbonetti NH, Sparling PF: Molecular cloning and characterization of the structural gene for protein I: the major outer membrane protein of Neisseria gonorrhoeae. Genetics 1987, 84:9084-9088.

13. Carbonetti NH, Simnad VI, Seifert HS, So M, Sparling PF: Genetics protein I of Neisseria gonorrhoeae: construction of hybrid porins. Genetics 1988, 85:6841-6845.

14. Heckels JE, Fletcher JN, Virji M: The potential protective effect of immunization with outer-membrane protein I from Neisseria gonorrhoeae. J Gen Microbiol 1989, 135:2269-2276.

15. Elkins C, Carbonetti NH, Varela VA, Stirewalt D, Klapper DG, Sparling PF: Antibodies to $\mathrm{N}$-terminal peptides of gonococcal porin are bactericidal when gonococcal lipopolysaccharide is not sialylated. Mol Microbiol 1992, 6:2617-2628.

16. Elkins C, Barkley KB, Carbonetti NH, Stirewalt D, Sparling PF: Immunobiology of purified recombinant outer membrane porin protein I of Neisseria gonorrhoeae. Mol Microbiol 1994, 14:1059-1075.

17. Swanson J, Dorward D, Lubke L, Kao D: Porin polypeptide contributes to surface charge of gonococci. J Bacteriol 1997, 179:3541-3548.

18. Kühlewein C, Rechner C, Meyer TF, Rudel T: Low-phosphate-dependent invasion resembles a general way for Neisseria gonorrhoeae to enter host cells. Infect Immun 2006, 74:4266-4273.

19. Mee BJ, Thomas H, Cooke SJ, Lambden PR, Heckels JE: Structural comparison and epitope analysis of outer-membrane protein PIA from strains of Neisseria gonorrhoeae with differing serovar specificities. I Gen Microbiol 1993, 139:2613-2620.

20. Unemo M, Olcén P, Jonasson J, Fredlund H: Molecular typing of Neisseria gonorrhoeae isolates by pyrosequencing of highly polymorphic segments of the porB gene. J Clin Microbiol 2004, 42:2926-2934.

21. Cooke SJ, Jolley K, Ison CA, Young H, Heckels JE: Naturally occurring isolates of Neisseria gonorrhoeae, which display anomalous serovar properties, express PIA/PIB hybrid porins, deletions in PIB or novel PIA molecules. FEMS Microbiol Lett 1998, 162:75-82.

22. Ilina EN, Malakhova MV, Vereshochagin VA, Govorun VM, Sergienko VI, Zubkov MM, Vasilev MM, Kubanova AA: Molecular typing of $N$. gonorrhoeae strains prevalent in the Russian Federation. Bull Exp Biol Med 2003, 136:179-182.

23. Mcknew DL, Lyun F, Zenilman JM, Bash MC: Porin variation among clinical isolates of Neisseria gonorrhoeae over a 10-year period, as determined by Por variable region typing. J Infect Dis 2003, 187:1213-1222.

24. Knapp JS, Tam MR, Nowinski RC, Holmes KK, Sandström EG: Serological classification of Neisseria gonorrhoeae with use of monoclonal antibodies to gonococcal outer membrane protein I. J Infect Dis 1984, 150:44-48.

25. Ison CA: Genotyping of Neisseria gonorrhoeae. Curr Opin Infect Dis 1998, 11:43-46. 
26. Thompson DK, Deal CD, Ison CA, Zenilman JM, Bash MC: A typing system for Neisseria gonorrhoeae based on biotinylated oligonucleotide probes to PIB gene variable regions. J Infect Dis 2000, 181:1652-1660.

27. Unemo M, Olcn P, Albert J, Fredlund $\mathrm{H}$ : Comparison of serologic and genetic porB-based typing of Neisseria gonorrhoeae: consequences for future characterization. J Clin Microbiol 2003, 41:4141-4147.

28. Unemo M, Vorobieva V, Firsova N, Ababkova T, Leniv I, Haldorsen BC, Rfedlund H, Skogen V: Neisseria gonorrhoeae population in Arkhangelsk, Russia: phenotypic and genotypic heterogeneity. Clin Microbiol Infect 2007, 13:873-878.

29. Viscidi RP, Demma JC, Gu J, Zenilman J: Comparison of sequencing of the por gene and typing of the opa gene for discrimination of Neisseria gonorrhoeae strains from sexual contacts. J Clin Microbiol 2000, 38:4430-4438.

30. Unemo M, Olcen P, Berglund T, Albert J, Fredlund H: Molecular epidemiology of Neisseria gonorrhoeae: sequence analysis of the porB gene confirms presence of two circulating strains. J Clin Microbiol 2002, 40:3741-3749.

31. Hobbs MM, Alcom TM, Davis RH, Fischer W, Thomas JC, Martin I, Ison C, Sparling PF, Cohen MS: Molecular typing of Neisseria gonorrhoeae causing repeated infections: evolution of porin during passage within a community. J Infect Dis 1999, 179:371-381.

32. Lynn F, Hobbs MM, Zenilman JM, Behets FM, Van Damme K, Rasamindrakotroka A, Bash MC: Genetic typing of the porin protein of Neisseria gonorrhoeae from clinical noncultured samples for strain characterization and identification of mixed gonococcal infections. J Clin Microbiol 2005, 43:368-375.

33. Martin IM, Ison CA, Aanensen DM, Fenton KA, Spratt BG: rapid sequencebased indentification of gonococcal transmission clusters in a large metropolitan area. J Infect Dis 2004, 189:1497-505

34. Gill MJ, Simjee $S$, Al-Hattawi K, Robertson BD, Easmon CS, Ison CA Gonococcal resistance to $\beta$-lactams and tetracycline involves mutation in loop 3 of the porin encoded at the penB locus. Antimicrob Agents Chemother 1998, 42:2799-2803.

35. Olesky M, Zhao S, Rosenberg RL, Nicholas RA: Porin-mediated antibiotic resistance in Neisseria gonorrhoeae: ion, solute, and antibiotic permeation through PIB proteins with penB mutations. J Bacteriol 2006, 188:2300-2308.

36. Sosa J, Ramirez-Arcos S, Ruben M, Li H, Llanes R, Llop A, Dillon JA: High percentages of resistance to tetracycline and penicillin and reduced susceptibility to azithromycin characterize the majority of strain types of Neisseria gonorrhoeae isolates in Cuba, 1995-1998. Sex Transm Dis 2003, 30:443-448.

37. Montgomery K, Raymundo L Jr, Drew WL: Chromogenic cephalosporin spot test to detect betalactamase in clinically significant bacteria. J Clin Microbiol 1979, 9:205-207.

38. Sambrook J, Russell DW: Molecular cloning, a laboratory manual. New York, Gold Spring Harbor Laboratory Press;, 2 2001:7:30-7, 35.

39. Cooke SJ, de la Paz H, La Poh C, Ison CA, Heckels JE: Variation within serovars of Neisseria gonorrhoeae detected by structural analysis of outer-membrane protein PIB and by pulsed-field gel electrophoresis. Microbiology 1997, 143:1415-1422.

40. Fudyk TC, Maclean IW, Simonsen JN, Njagi EN, Kimani J, Brunham RC, Plummer FA: Genetic diversity and mosaicism at the por locus of Neisseria gonorrhoeae. J Bacteriol 1999, 181:5591-5599.

41. Arreaza L, Salcedo C, Alcalá B, Berrón S, Martín E, Vázquez JA: Antibiotic resistance of Neisseria gonorrhoeae in Spain: trends over the last two decades. J Antimicrob Chemother 2003, 51:153-156.

42. Ng LK, Martin I, Lau A, the National Gonococcal Surveillance Program Members: Trends of chromosomally mediated antimicrobial resistance in Neisseria gonorrhoeae in Canada: 1994-1999. Sex Transm Dis 2003, 30:896-900.

43. Zhu W, Thomas CE, Sparling PF: DNA immunization of mice with a plasmid encoding Neisseria gonorrhea PorB protein by intramuscular injection and epidermal particle bombardment. Vaccine 2004, 22:660-669.

44. Bash MC, Zhu P, Gulati S, McKnew D, Rice PA, Lynn F: por Variable-region typing by DNA probe hybridization is broadly applicable to epidemiologic studies of Neisseria gonorrhoeae. J Clin Microbiol 2005, 43:1522-1530
45. De La Fuente L, Va'zquez JA: Multilocus enzyme analysis of African type penicillinase-producing Neisseria gonorrhoeae (PPNG) strains isolated in Spain. Sex Transm Dis 1991, 18:150-152.

46. Gill MJ, Jayamohan J, Lessing MP, Ison CA: Naturally occurring PIA/PIB hybrids of Neisseria gonorrhoeae. FEMS Microbiol Lett 1994, 119:161-166.

47. Olesky M, Hobbs M, Nicholas RA: Identification and analysis of amino acid mutations in porin IB that mediate intermediate-level resistance to penicillin and tetracycline in Neisseria gonorrhoeae. Antimicrob Agents Chemother 2002, 46:2811-2820.

48. Hagman KE, Pan W, Spratt BG, Balthazar JT, Judd RC, Shafer WM: Resistance of Neisseria gonorrhoeae to antimicrobial hydrophobic agents is modulated by the mtrRCDE efflux system. Microbiology 1995, 141:611-622.

49. Lindberg $\mathrm{R}$, Fredlund $\mathrm{H}$, Nicholas $\mathrm{R}$, Unemo M: Neisseria gonorrhoeae isolates with reduced susceptibility to cefixime and ceftriaxone: association with genetic polymorphisms in penA, mtrR, porB1b, and ponA. Antimicrob Agents Chemother 2007, 51:2117-2122.

50. Zhao S, Duncan M, Tomberg J, Davies C, Unemo M, Nicholas RA: Genetics of chromosomally mediated intermediate resistance to ceftriaxone and cefixime in Neisseria gonorrhoeae. Antimicrob Agents Chemother 2009, 53:3744-3751.

51. Woodford N, Bindayna KM, Easmon CS, et al: Associations between serotype and susceptibility to antibiotics of Neisseria gonorrhoeae. Genitourin Med 1989, 65:86-91.

52. Yang $Y$, Liao M, Gu W, Bell K, Wu L, Eng NF, Zhang CG, Chen Y, Jolly AM, Dillon JAR: Antimicrobial susceptibility and molecular determinants of quinolone resistance in Neisseria gonorrhoeae isolates from Shanghai. $J$ Antimicrob Chemother 2006, 58:868-872.

53. Liao MM, Bell K, Gu WM, Yang Y, Eng NF, Fu WK, Wu L, Zhang CG, Chen Y, Jolly AM, Dillon JAR: Clusters of circulating Neisseria gonorrhoeae strains and association with antimicrobial resistance in Shanghai. J Antimicrobial Chemother 2008, 61:478-87.

54. Chalkley $\amalg$, van Vuuren S, Ballard RC, Botha PL: Characterisation of penA and tetM resistance genes of Neisseria gonorrhoeae isolated in southern Africa-epidemiological monitoring and resistance development. $S$ Afr Med J 1995, 85:775-780.

55. Ropp PA, Hu M, Olesky M, Nicholas RA: Mutations in ponA, the gene encoding penicillin-binding protein 1 , and a novel locus, penC, are required for high-level chromosomally mediated penicillin resistance in Neisseria gonorrhoeae. Antimicrob. Agents Chemother 2002, 46:769-777.

56. Hu M, Nandi S, Davies C, Nicholas RA: High-level chromosomally mediated tetracycline resistance in Neisseria gonorrhoeae results from a point mutation in the rpsJ gene encoding ribosomal protein S10 in combination with the $\mathrm{mtrR}$ and penB resistance determinants. Antimicrob Agents Chemother 2005, 49:4327-4334.

57. Liao MM, Helgeson S, Gu WM, Yang Y, Jolly AM, Dillon JAR: Comparison of Neisseria gonorrhoeae multiantigen sequence typing and porB sequence analysis for identification of clusters of $N$. gonorrhoeae isolates. J Clin Microbiol 2009, 47:489-491.

\section{Pre-publication history}

The pre-publication history for this paper can be accessed here: http://www.biomedcentral.com/1471-2334/10/323/prepub

doi:10.1186/1471-2334-10-323

Cite this article as: Sun et al:: Predominant porB1A and porB1B genotypes and correlation of gene mutations with drug resistance in Neisseria gonorrhoeae isolates in Eastern China. BMC Infectious Diseases 2010 10:323. 